Светиков Сергей Александрович

Svetikov Sergey Aleksandrovich

соискатель

Адыгейского государственного университета

\section{КРИТЕРИИ И ФАКТОРЫ СОЦИАЛЬНОГО НЕРАВЕНСТВА}

External PhD student, Adyghe State University

\section{CRITERIA AND FACTORS OF} SOCIAL INEQUALITY
Аннотация:

Одной из серьезных проблем современного общества является социальное неравенство. При этом оно становится как реальной проблемой, так и объектом многочисленных политических спекуляций. Наличие неравенства в социуме определяет деструктивный потенциал общественной структуры, в то время как уровень обращения к данному вопросу в рамках информационного пространства зачастую отвечает за реализацию этого деструктивного потенциала. В статье рассматриваются три основных аспекта актуализации проблемы неравенства: объективные факторы социальной стратификации; усугубление неравенства, обусловленное структурными нарушениями в обществе; а также характер социальных установок населения как фактор актуализации проблемы неравенства. На основе представленного обзора сделаны выводы относительно текущей ситуации, связанной с неравенством, перспектив ее развития и возможных направлений государственного регулирования.

Ключевые слова:

неравенство, социальные возможности, стратификация, социальная справедливость, социальные институты, общественное мнение, деструктивный потенциал общества, социальный конфликт.
Summary:

One of the major issues of modern society is social inequality. At the same time, inequality becomes both a real problem and the subject of numerous political speculation. Social inequality determines the destructive capacity of public structure while the level of the appeal to this problem within the information space of society often defines the implementation of this destructive potential. The study considers three main aspects of updating inequality problems: objective factors of social stratification, inequality aggravation connected with structural violations in society, and the nature of the social attitudes of the population as a factor of updating inequality issue. Based on the review provided, the author describes the current situation of inequality, the prospects of its development, and the possible areas of state regulation.

Категория социального неравенства имеет высокую степень значимости в социальном дискурсе. Это связано с тем, что различия в уровне социальных возможностей членов общества формируют в социальной среде негативный отклик, проявляющийся в возрастании конфликтогенного потенциала общества и снижении его устойчивости по отношению к внешним дестабилизирующим воздействиям.

Проявления неравенства различны: от увеличения уровня преступности, связанного с попытками неправового перераспределения социальных благ, вплоть до возникновения внутрисоциальной конфронтации, обусловленной формированием и обособлением социальных групп, различающихся по статусной определенности и доступности социальных возможностей [1]. Критической точкой данного процесса становится ситуация, когда групповое самосознание начинает доминировать над гражданским, что приводит к легализации в рамках социального мировоззрения деструктивных действий, направленных на представителей других групп. Следует отметить, что практически любая форма актуализации социального неравенства (кроме его проблематизации среди представителей управленческой структуры общества и в области научного дискурса) несет в себе существенный деструктивный потенциал, что объясняется дискредитацией государства и культивацией социальной конфликтности. В связи с этим приобретает значимость постановка вопроса о способах противодействия рассматриваемому деструктивному явлению, что с необходимостью предполагает его анализ, в частности определение ведущих фракторов возникновения неравенства в социуме.

В исследовательской практике неравенство как предмет изучения характеризуется значительной неоднородностью по критерию степени разработки его отдельных аспектов. С одной стороны, имеют место классические работы Э. Дюркгейма [2], Т. Парсонса [3], Р. Мертона [4], раскрывающие специфику функциональной дифференциации развивающегося общества и связанного с нею неравенства на общетеоретическом уровне. С другой стороны, термин «неравенство» прочно вошел в научное употребление и рассматривается как нечто самоочевидное, в связи с чем имеет место частота контекстуального употребления понятия без дополнительного 
пояснения. Кроме того, существует ряд работ, направленных на раскрытие текущей ситуации неравенства в российском обществе. К их числу относятся труды М.К. Горшкова [5], 3.Т. Голенковой [6], а также коллективная монография «Модернизация структуры российского общества», выполненная на базе ИС РАН такими авторами, как З.Т. Голенкова, М.Ф. Черныш, А.Ш. Жвитиашвили, Е.Г. Мешкова, П.М. Козырева, З.Е. Дорофеева, Е.Д. Игитханян, И.М. Орехова, Т.И. Горина, В.А. Мансуров, О.В. Юрченко, Г.Л. Воронин, И.Ф. Дементьева, А.А. Хагуров, М.Н. Муханова, Л.А. Семенова, О.А. Андросова, Ю.В. Голиусова. Она посвящена детализации актуальной ситуации неравенства посредством аналитического обзора массива эмпирических данных по состоянию российского социума [7].

Несмотря на то что факт обращения научного сообщества к тематике неравенства налицо, возникает существенная проблема, связанная с недостаточностью осмысления механизмов формирования неравенства и факторов актуализации скрытого в нем деструктивного потенциала на фоне высокого уровня научной репрезентации текущих проблемных процессов. Понимание данных механизмов имеет не только высокую теоретическую значимость, но и практическую, поскольку может способствовать выработке эффективной стратегии противодействия проблеме. На заполнение данного пробела направлена настоящая статья.

Неравенство в обществе не может быть изжито полностью, поскольку его структура на современном этапе развития предполагает наличие иерархически выстроенных социальных подсистем, а сферы социальной деятельности различаются по степени значимости для общества в целом. Сравнение социальных показателей населения в разных странах по критериям уровня доходов, качества жизни, власти, престижа, образования, характеру досуга показало, что степень развития неравенства вариативна [8] и не имеет прямой привязки к уровню развития социума в целом. Эта вариативность выступает основанием, определяющим практическую значимость постановки вопроса о критериях неравенства и механизмах его проявления в обществе. Прежде чем приступить к обзору проблемы, следует обратить внимание на важный момент: не все формы неравенства расцениваются членами общества как негативное явление. Рассмотренные деструктивные тенденции связаны с ситуацией, при которой понятие неравенства анализируется в противоречии с категорией социальной справедливости. Постановка вопроса о взаимосвязи развитой структуры общества (и наличия в ней иерархических связей) и уровня стратификации свидетельствует о необходимости неравнозначного распределения социальных позиций.

Обозначенные факторы позволяют сформулировать следующую гипотезу: актуализация проблемы социального неравенства связана с расхождением между уровнем стратификации, детерминированными актуальными структурными запросами общества и степенью распределения социальных благ и возможностей. Наиболее интенсивно социальное неравенство проявляется в ситуациях, когда показатели неравенства значительно превышают детерминированные текущими развитием и структурой общества нормы расхождения социальных позиций. Вместе с тем справедливо и следующее замечание: анализ адекватного уровню развития общественной структуры характера неравенства представляет собой сложную теоретическую задачу, решение которой недоступно большинству членов социума. При этом оценку реализации «социальной справедливости» осуществляет большинство представителей общественной структуры. В данном смысле справедливо суждение о том, что деструктивный потенциал неравенства связан также с расхождением между актуальной ситуацией распределения социальных благ и возможностей и сформированной в рамках общественного сознания моделью. Последнее служит классическим проявлением обратной связи между социальным познанием и процессами социального конструирования.

Таким образом, мы приходим к пониманию трех взаимосвязанных аспектов вопроса социального неравенства: проблемы объективных оснований неравномерного распределения социальных благ и возможностей среди членов общества; проблемы отклонений уровня неравенства в конкретной социальной системе от объективно определенного текущими характеристиками эпохи и политического строя (что представляет собой увеличение или уменьшение уровня неравенства, обусловленное снижением эффективности структуры социума); проблемы адекватности социальных оценок значимости (и, следовательно, уровня социальной награды) разных форм общественной активности.

Данное теоретическое разделение свидетельствует, в частности, о том, что возможны ситуации, при которых адекватное текущему уровню развития общества распределение социальных благ может сопровождаться существенным деструктивным общественным резонансом, связанным с противоречием между социальными ожиданиями населения и реальной практикой. Напротив, вероятна и ситуация, когда неадекватное распределение социальных благ в сочетании с соответствующей деформацией общественного сознания сводит на нет общественный резонанс относительно неравенства и, следовательно, определяет сохранение социального порядка в неизменном виде. Это отражает значимость рассмотренных проблем, поскольку речь идет о вариативных аспектах развития общественной структуры. 
Обратимся к тематике объективных оснований развития социального неравенства. Данный вопрос имеет чрезвычайно высокий уровень теоретической разработанности ввиду того, что напрямую связан с одной из центральных проблем социологического дискурса - социальной стратификацией. Существуют следующие фракторы, определяющие необходимость неравномерного распределения социальных благ и возможностей: различная степень приоритетности социальной деятельности (при сходном уровне затрат усилий, времени и т. д.); иерархичность социальных подсистем; зависимость социального вознаграждения от сложности осуществляемой деятельности; степень конкуренции в разных профессиональных сфрерах; иные институциональные факторы распределения социальных возможностей.

Набор определяющих фракторов неравенства различается в зависимости от того, по какому критерию оценивается возникновение неравенства. Например, рассмотрение уровня властных отношений обусловливает приоритетность иерархичности общественной структуры и зависимость уровня власти от личных и профессиональных качеств того или иного человека, тогда как рассмотрение материального вознаграждения игнорирует момент иерархичности отношений и сконцентрировано в первую очередь на анализе прагматики социальной активности члена общества и степени востребованности его действий в рамках общественной структуры.

Так или иначе, чем выше уровень развития общественной структуры, тем больше концентрация власти и капитала в руках малых, но крайне влиятельных групп. Это представляет собой закономерный результат общественного развития и в некоторой степени выражает потребность общества в наличии централизованных структур по обеспечению управленческих, производственных и иных функций, удовлетворяющих требования политического режима [9]. Однако степень развития общества представляет собой лишь исходное условие, определяющее тенденцию распределения социальных благ и расхождение формирующихся позиций. Не меньшее значение имеет эффрективность институциональной структуры социума [10, с. 56-64]. Сам по себе термин «неравенство» предполагает наличие существенных расхождений в средствах и возможностях. Однако речь может идти как о мере превышения нормы отдельными членами социума, так и о наличии ненормально низких возможностей, что служит результатом неадекватного функционирования основных социальных институтов. Высокий уровень социальной стратификации выступает нормой практически для любого современного общества, в то время как высокий уровень распространенности нищеты, необразованности, правовой ущемленности представляет собой деструктивное, отклоняющееся от нормы функционирования общества явление, подлежащее локализации и устранению [11].

Как показано ранее, существуют разные критерии социального неравенства - по уровню материального достатка, образованности, власти, престижа и личной свободы. Все эти измерения рассмотрения социального неравенства связаны с институтами экономики, политики, образования, здравоохранения и права, а также с культурно-информационными процессами, в рамках которых происходит локальное и широкомасштабное формирование общественного мнения. Данные разновидности неравенства (соответственно, и критериев его определения) представляют собой производные функции от состояния основных социальных институтов. Таким образом, проблема неравенства как утраты членами общества нормального набора возможностей фактически сводится к вопросу о снижении эффективности институциональной сфреры общества, результатом которого становится возрастание степени социальной деструктивности [12].

Оптимизация социальной среды в данном случае выступает основанием для снижения уровня неравенства и восстановления системы отношений в том виде, какой предполагает текущая стадия развития общества. Социальные позиции не могут быть полностью усреднены, что вполне соотносится с различиями индивидуальных способностей и личностных качеств, имеющих профессиональное и социальное значение. Вместе с тем разрешение проблемы социального неравенства, связанное с оптимизацией институциональной сферы, выражено в устранении тенденции формирования широких групп ущемленного населения и переводе ряда членов социума в средний класс (как минимум по уровню экономических возможностей и качества жизни).

В обозначенной системе координат чрезвычайно большое значение приобретает отражение ситуации в общественном мнении, в частности оценка членами общества норм вознаграждения общественно полезной активности. Представления о «социальной справедливости», лежащие в основе протестных тенденций, ориентированных на вскрытие проблемы неравенства, предполагают внутренние критерии соотношения социальной активности и связанных с нею социальных поощрений. Наблюдается синтетическое объединение таких факторов, как риск при осуществлении деятельности; социальная значимость анализируемой сфреры деятельности; профессиональные требования, предъявляемые к субъекту деятельности; личная оценка качества жизни носителей общественного мнения.

Последнее представляет собой один из важнейших факторов, определяющих характер общественного мнения. Фактически степень социальной удовлетворенности субъектов оценки, 
складывающаяся из личных притязаний и характера текущей ситуации, отражает их реакцию на социальный рост других членов общества (и их успешность в целом). С учетом того что психологически более простым шагом выступает усмотрение причины различий не в низком уровне личных качеств, а в характере внешних обстоятельств, наличие социальной неудовлетворенности членов социума является серьезным фрактором актуализации проблемы социальной справедливости и некорректности общественной структуры.

Все это в совокупности свидетельствует о том, что отрицательный общественный резонанс, связанный с социальным неравенством, в первую очередь детерминирован состоянием «низов» и их расхождением с усредненными нормами социальной жизни, принятыми в качестве критериев состоятельности человека в обществе. В свою очередь негативные отклонения в уровне социальных возможностей населения представляют собой одно из следствий нарушения институциональной сферы. Таким образом, снижение деструктивного потенциала социального неравенства связано с изменением общих установок социального сознания и оптимизацией институциональной сферы общества в целях «подтягивания» наиболее ущемленных социальных групп до усредненных показателей социальной устроенности.

\section{Ссылки:}

1. Голенкова 3.Т. Социальная дифференциация и социальное неравенство населения // Вестник Тюменского государственного университета. Социально-экономические и правовые исследования. 2011. № 8. С. 162-168.

2. Дюркгейм Э. О разделении общественного труда. М., 1996.

3. Парсонс Т. Система современных обществ / пер. с англ. Л.А. Седова, А.Д. Ковалева ; под ред. М.С. Ковалевой. М., 1998. $270 \mathrm{c}$

4. Мертон Р.К. Социальная теория и социальная структура. M., 2006. 873 с. ; Merton R.K. The Sociology of Science: Theoretical and Empirical Investigations. Chicago, 1973. 605 p.

5. Горшков М.К. Социальные неравенства как вызов современной России // Вестник Института социологии. 2010. № 1. C. 24-47.

6. Голенкова 3.Т. Указ. соч.

7. Модернизация структуры российского общества / З.Т. Голенкова, М.Ф. Черныш, А.Ш. Жвитиашвили и др. М., 2008.

8. Горшков М.К. Указ. соч

9. Нарыков Н.В. К проблеме типизации политических режимов // Теория и практика общественного развития. 2009 . № 3-4.

10. Мертон Р.К. Указ. соч. С. 56-64.

11. Merton R.K. Op. cit.

12. Кубякин Е.О., Плотников В.В. Феномен дестабилизации локальной социальной системы (государства) // Научный вестник Омской академии МВД России. 2015. № 4 (59) ; Плотников В.В. Трансформация социальных институтов как генетический фрактор феномена экстремизма. Краснодар, 2016. 228 с.

\section{References:}

Durkheim, E 1996, The division of labour in society, Moscow, (in Russian).

Golenkova, ZT 2011, 'Social differentiation and social inequality of the population', Vestnik Tyumenskogo gosudarstvennogo universiteta. Sotsial'no-ekonomicheskiye i pravovyye issledovaniya, No. 8, pp. 162-168, (in Russian).

Golenkova, ZT, Chernysh, MF \& Zhvitiashvili ASh (et al.) 2008, Modernization of the structure of Russian society, Moscow, (in Russian).

Gorshkov, MK 2010, 'Social inequalities as a challenge to modern Russia', Vestnik Instituta sotsiologii, No. 1, pp. 24-47, (in Russian).

Kubyakin, EO \& Plotnikov, VV 2015, 'The phenomenon of destabilization of the local social system (state)', Nauchnyy vestnik Omskoy akademii MVD Rossii, No. 4 (59), (in Russian).

Merton, RK 1973, The Sociology of Science: Theoretical and Empirical Investigations, Chicago, 605 p.

Merton, RK 2006, Social theory and social structure, Moscow, 873 p., (in Russian).

Narykov, NV 2009, 'Problem typification of the political regime', Teoriya i praktika obshchestvennogo razvitiya, No. 3-4, (in Russian).

Parsons, T, Sedov, LA, Kovalev, AD (transl.) \& Kovaleva, MS (ed.) 1998, The system of modern societies, Moscow, 270 p., (in Russian).

Plotnikov, VV 2016, Transformation of social institutions as a genetic factor of the extremism phenomenon, Krasnodar, $228 \mathrm{p}$, (in Russian). 